\title{
Applying fuzzy multi-criteria decision method to evaluate the credibility ranking for Taiwan banks' potential debtors from the viewpoint of default probability-A Taiwan LCD panels industry case
}

\author{
Yang-Cheng $\mathrm{Lu}^{1} \quad$ Yaw-Chu Chen ${ }^{2}$ \\ ${ }^{1}$ Finance Department, Ming Chuan University \\ ${ }^{2}$ Department of Advertising, Ming Chuan University
}

\begin{abstract}
The purpose of this paper is to provide an algorithm for commercial banks in Taiwan to evaluate the credibility of their potential debtors from the default probability viewpoint under fuzzy environment. The fundamental concepts we have adopted include the eigenvector method, fuzzy Delphi method, fuzzy set theory, and multi-criteria decision making method. By coordinating the concept of internal credit rating approach proposed by Basel II and the interviewing senior managers of bank industry in Taiwan, we propose four major criteria and forty sub-criteria to construct the hierarchical structure for evaluating the banks' potential debtors' credibility. The fuzzy Delphi method is integrated with the eigenvector method to form a set of pooled weights of the criteria. The concepts of triangular fuzzy number and linguistic variables are used to assess the preference ratings, including 'importance' and 'appropriateness', of linguistic variable. Through the hierarchy integration, we obtain the final scores of credibility, and then use a revised Chang and Chen's ranking method for evaluating the ranking of debtors' credibility.
\end{abstract}

Keywords : Credibility, Default probability, Basel II, Fuzzy multi-criteria decision making, LCD panel, Bank industry.

\section{Introduction}

The New Basel Capital Accord (Basel II) allows the determination of banks' regulatory capital requirements due to default probabilities (PDs) which are estimated and forecasted from internal ratings. Banks will be required to estimate a one-year PD for each obligor [2]. Of course, 'true' PDs can be assumed to follow a continuous process and might thus be different for each counterparty. But in practice, true PDs are unknown and can only be estimated through rating systems. Rating systems can be statistical models or expert-based approaches (most of the time they are a combination of both) that classify obligors in different rating categories. Estimated PDs can sometimes be inferred from equity prices, bond spreads or logit/probit/tobit based econometric models, but historical default experience will usually be used as the most reasonable estimate. So, banks will have groups of counterparties that are in the same rating class (and then have the same estimated PD and credibility ranking derived from historical data) and will have to check if the default rates they observe each year are consistent with their estimation of the long run average one-year PD and credibility ranking.

The new credit risk measurement regulations suggested by Basel II has compelled the banks to refine the evaluation model for rating the credibility of their potential debtors by incorporate both of the quantitative and quantitative criteria. Based on Basel II, financial regulators in the matured economies start to promote the criteria that depends on experts' judgment, such as some of the corporate governance criterions, to further evaluate the credibility of any public offered company $[1,6,7,11,12,13,15,16,19]$.

Most non-financial measures are qualitative by nature and often depend on experts' judgment of approximation [3]. Such factors involve a great degree of linguistic deficiency [10]; in other words, we cannot elicit the complete, precise, and reliable knowledge from the experts. Due to the existing fuzziness in credibility evaluation and decision making as mentioned above, a fuzzy approach appears to be one of the feasible solutions for us to handle such difficult problems. In this paper, an algorithm for evaluating key credibility of banks' potential debtors is proposed on the basis of fuzzy set theory [17], paired comparison judgments of analytic hierarchy process [14] and fuzzy Delphi method [9]. The normal triangular fuzzy numbers [8] and the linguistic values are utilized to assess the preference ratings of linguistic variables [18]. Section 2 discusses sources of sub-criteria. Section 3 presents the methodology of this paper. Section 4 presents a Taiwan case study of listed companies key credibility evaluation, where as Section 5 is the concludes this paper. 


\section{Sources of sub-criteria}

Reviewing literatures $[1,2,6,7,11,12,13,15,16,19]$ and interviewing Taiwan bank industry officers, we collect forty sub-criteria. We used Likert seven point scales to evaluate the importance of sub-criteria. In this paper, the threshold level is $70 \%$, that is, the sub-criteria which the geometric mean values are less than 4.9 were removed. The evaluating sub-criteria are described below.

(1)Financial Performance $\left({ }^{1} C_{1}\right):\left\{\right.$ Debt ratio $\left({ }^{2} C_{1}\right)$, Cash flow ratio $\left({ }^{2} C_{2}\right)$, Return on total assets $\left({ }^{2} C_{3}\right)$, Operating profit margin $\left({ }^{2} C_{4}\right)$, Gross profit margin $\left({ }^{2} C_{5}\right)$, Long-term equity investment to net worth $\left({ }^{2} C_{6}\right)$, Earnings per share $\left({ }^{2} C_{7}\right)$, Return on Equity $\left({ }^{2} C_{8}\right)$, Account receivable turnover $\left({ }^{2} C_{9}\right)$, Earnings before Interest, Taxes, Depreciation, and Amortization $\left({ }^{2} C_{10}\right)$, Interest Coverage ratio $\left({ }^{2} C_{11}\right)$, Quick Ratio $\left({ }^{2} C_{12}\right)$, accounts receivable and billsaffiliated person $\left.\left({ }^{2} C_{13}\right)\right\}$.

(2) Governance Structure $\left({ }^{1} C_{2}\right):\{$ Voting rights of controlling shareholder $\left({ }^{2} C_{14}\right)$, Cash flow rights of controlling shareholder $\left({ }^{2} C_{15}\right)$, Management participation $\left({ }^{2} C_{16}\right)$, Cross-holding $\left({ }^{2} C_{17}\right)$, Pyramid structure $\left({ }^{2} C_{18}\right)$, Family-controlled $\left({ }^{2} C_{19}\right)$, Directors ownership $\left({ }^{2} C_{20}\right)$, Stock pledge ratio of directors

$\left({ }^{2} C_{21}\right)$, level of directors' ownership $\left({ }^{2} C_{22}\right)$, level of stock pledge $\left({ }^{2} C_{23}\right)$, Cross effect between directors ownership and level of stock pledge $\left({ }^{2} C_{24}\right)$, Cross effect between stock pledge ratio of directors and level of stock pledge $\left({ }^{2} C_{25}\right)$, Cross effect between level of directors' ownership and level of stock pledge $\left({ }^{2} C_{26}\right)$, Frequency of changing financial officer or accountant $\left({ }^{2} C_{27}\right)$, Information quality of financial statement $\left.\left({ }^{2} C_{28}\right)\right\}$.

( 3 ) Macroeconomic Environment $\left({ }^{1} C_{3}\right)$ : \{ Long-short term interest rate spread $\left({ }^{2} C_{29}\right)$, Composite score of leading indicators $\left({ }^{2} C_{30}\right)$, Composite score of coincidental indicators $\left({ }^{2} C_{31}\right)$, Annual M2 growth $\left({ }^{2} C_{32}\right)$, Annual M1b growth $\left({ }^{2} C_{33}\right)$, Annual CPI growth $\left({ }^{2} C_{34}\right)$, Annual IPI growth $\left({ }^{2} C_{35}\right)$, Exchange rate $\left({ }^{2} C_{36}\right)$,Unemployment rate $\left.\left({ }^{2} C_{37}\right)\right\}$.

(4) Probability of Default $\left({ }^{1} C_{4}\right):\{$ Default point $\left({ }^{2} C_{38}\right)$, Distance to Default $\left.\left({ }^{2} C_{39}\right), \operatorname{Net} \operatorname{debt}\left({ }^{2} C_{40}\right)\right\}$.

\section{Method}

This section gives a fuzzy algorithm for evaluating the credibility of potential debtors of commercial banks in Taiwan as a background for further application. The triangular fuzzy number and linguistic variable are the two main concepts used in this paper to assess the preference ratings of linguistic variables, 'importance' and 'appropriateness'. The top decision makers can employ an assumed weighting set $W=\{$ Very Low, Low, Medium, High, Very High $\}$ to assess the relative importance of various criteria. And use the linguistic rating set $S=\{$ Very Poor, Poor, Fair, Good, Very Good $\}$ to evaluate the appropriateness of the alternatives versus various criteria. The membership functions of linguistic values in the weighting set $W$ and the linguistic rating set $S$ can be represented by approximate reasoning of triangular fuzzy numbers, as shown in Table 1[5].

Table 1. Membership functions for linguistic values

\begin{tabular}{ll}
\hline Linguistic values & Fuzzy numbers \\
\hline Very low (VL),Very poor (VP) & $(0,0,0.25)$ \\
Low (L), Poor (P) & $(0,0.25,0.5)$ \\
Medium (M), Fair (F) & $(0.25,0.5,0.75)$ \\
High (H), Good (G) & $(0.5,0.75,1)$ \\
Very high (VH), Very good (VG) & $(0.75,1,1)$ \\
\hline
\end{tabular}

A more general representation of multi-criteria decision making problem is introduced. Supposed there is a committee of $n$ decision makers $\left(D_{1}, D_{2}, \ldots\right.$, $D_{n}$ ) who are responsible for assessing the appropriateness of $m$ alternatives $\left(A_{1}, A_{2}, \ldots, A_{m}\right)$ under each of $k$ criteria $\left({ }^{h} C_{t}, t=1,2, \ldots, k, h=1,2\right.$; where $h=1$ means criteria and $h=2$ means sub-criteria) as well as the importance weight of the criteria. Let the $S_{i t j}(i=1,2, \ldots, m ; t=1,2, \ldots, k ; j=$ $1,2, \ldots, n)$ be the rating assigned to alternatives $A_{i}$ by decision maker $D_{j}$ under criterion ${ }^{h} C_{t}$. An algorithm of the multi-person multi-criteria listed companies key credibility evaluation with fuzzy set approach can be expressed by the following steps :

Step 1. Construction of hierarchical structure

(1) Form a committee of decision makers, and then identify the evaluation criteria and alternative capabilities of listed companies.

(2) Construct the hierarchical structure of listed companies key credibility evaluation through the concept of Basel II .

Step 2. Evaluation of the importance weight of each criterion

(3) Use fuzzy Delphi method to determine the fuzzy number of pooled weight of each criterion.

Step 3. Construction of linguistic scales for linguistic variables

(4) Choose the appropriate preference ratings for the importance weight of the evaluation criterion.

(5) Select the appropriateness ratings for alternatives under sub-criteria.

Step 4. Aggregation of fuzzy appropriateness indices

(6) Aggregate the weight of sub-criterion to get the aggregated weight ${ }^{2} W_{t}$.

(7) Pool the decision makers' opinions to get the aggregated fuzzy rating $S_{i t}$ of alternative $A_{i}$ under each sub-criterion ${ }^{2} C_{t}$.

(8) Aggregate $S_{i t}$ and ${ }^{2} W_{t}$ with respect to each sub-criterion to obtain the fuzzy appropriateness indices $R_{i}$ for all alternatives.

Step 5. Computation of fuzzy overall evaluation 
(9) Aggregate polled weight $\left({ }^{1} W_{t}\right)$ of criteria with fuzzy appropriateness indices $\left(R_{i}\right)$ to obtain the fuzzy overall evaluation $\left(F_{i}\right)$ of each alternative.

Step 6. Defuzzification of fuzzy overall evaluation

(10)Calculate the ranking value $U_{T}\left(F_{i}\right)$ by defuzzifying the fuzzy overall evaluation through ranking method.

Step 7. Analysis and decision

(11)Choose the capability of listed companies with the maximal ranking value.

\section{An application}

The case study is implemented form the five LCD panel manufacturing companies in Taiwan, say Chunghwa Picture Tubes Ltd., Chi Mei Optoelectronics Corp., Quanta Display Inc., Hannstar Display Corp. and Auo Optronics corp. The LCD panel industry has become one of the most energetic industries in Taiwan. Up to the end of 2005, total manufacturing values of LCD panels of Taiwan has also taken place the largest market shares in the global supply chain. Hence we apply our model to evaluate the credibility of the five LCD panel manufacturing companies in Taiwan.

\section{Step 1.}

A committee of four bank's decision makers, $D_{1}$, $D_{2}, D_{3}$ and $D_{4}$, has been formed to determine the key determinant of credibility of those listed companies in Taiwan. They are deputy manager of credit bureau, deputy manager of corporate finance department, deputy manger of research department and deputy manager of risk management department. There are four major criterions of for the selected LCD companies in this case study. The four major criteria are financial performance, governance structure, macroeconomic environment, and probability of default.

Step 2.

There are some easy ways to obtain a good approximation of the priorities. One of the best ways is the geometric mean [14]. By normalizing of geometric mean of the rows and using fuzzy Delphi concept [9], we can derive the final weights for the criteria of level 2. Due to the property of fuzzier in criteria than in sub-criteria, we use triangular fuzzy number to aggregate the decision makers' assessments and geometric mean to obtain fuzzy weight ${ }^{1} W_{t}$. Define

$$
{ }^{1} W_{t}=\left(e_{t}, f_{t}, g_{t}\right)
$$

where ${ }^{1} W_{t}$ is the fuzzy weight under criterion $t$,

$$
e_{t}=\min _{j}\left\{W_{j t}\right\}, \quad g_{t}=\max _{j}\left\{W_{j t}\right\}, f_{t}=\left(\prod_{j=1}^{n}{ }^{1} W_{j t}\right)^{1 / n},
$$

$t=1,2, \ldots, 4, \quad j$ are decision makers.
By using equation (1), we obtain the importance of the criteria as shown in Table 2.

Table 2. The importance of the criteria

\begin{tabular}{ll}
\hline Criteria & Weight \\
${ }^{1} C_{1}$ & ${ }^{1} W_{1}=(0.2911,0.3312,0.3950)$ \\
${ }^{1} C_{2}$ & ${ }^{1} W_{2}=(0.0837,0.1373,0.1864)$ \\
${ }^{1} C_{3}$ & ${ }^{1} W_{3}=(0.1733,0.2500,0.3754)$ \\
${ }^{1} C_{4}$ & ${ }^{1} W_{4}=(0.2168,0.2610,0.3001)$ \\
\hline
\end{tabular}

Step 3.

The decision makers can use the importance weighting set $W$ and appropriateness ratings set $S$ described in Table 1, to evaluate the importance weight ${ }^{2} W_{t}$, and the appropriateness ratings $S_{i t}$ for candidates under sub-criteria, respectively.

Step 4.

We will use the mean operator to aggregate the decision makers assessments. Let $\oplus$ and $\otimes$ be fuzzy addition and multiplication operators respectively. Define

$$
\begin{aligned}
& S_{i t}=\left(\frac{1}{n}\right) \otimes\left(S_{i t 1} \oplus S_{i t 2} \oplus \cdots \oplus S_{i t j} \oplus \cdots \oplus S_{m k n}\right) \\
& { }^{2} W_{t}=\left(\frac{1}{n}\right) \otimes\left({ }^{2} W_{t 1} \oplus^{2} W_{t 2} \oplus \cdots \oplus^{2} W_{t j} \oplus \cdots \oplus^{2} W_{k n}\right)
\end{aligned}
$$

where $S_{i t}$ is the average fuzzy appropriateness rating of alternative $A_{i}$ under sub-criterion ${ }^{2} C_{t}$ and ${ }^{2} W_{t}$ is average importance weight of sub-criterion ${ }^{2} C_{t}$. Thus the fuzzy appropriateness index $R_{i}$ of the alternative can be obtained by aggregating $S_{i t}$ and ${ }^{2} W_{t}$ denoted as

$$
\begin{aligned}
& R_{i}=\left(\frac{1}{k}\right) \otimes\left[\left(S_{i 1} \otimes^{2} W_{1}\right) \oplus\left(S_{i 2} \otimes^{2} W_{2}\right) \oplus \cdots \oplus\left(S_{i t} \otimes^{2} W_{t}\right) \oplus \cdots \oplus\left(S_{i k} \otimes^{2} W_{k}\right)^{-}\right. \\
& \cong\left(Y_{i}, Q_{i}, Z_{i}\right)
\end{aligned}
$$

\section{Step 5.}

The fuzzy overall evaluation of the five alternatives as shown in Table 3 can be obtain by multiplying $R_{i}$ and ${ }^{1} W_{t}$ can denoted as

$$
F_{i} \cong R_{i} \otimes{ }^{1} W_{t} \cong\left(Y_{i}^{\prime}, Q_{i}{ }^{\prime}, Z_{i}{ }^{\prime}\right)
$$

where $Y_{i}^{\prime}=Y_{i} \times e_{t}, Q_{i}^{\prime}=Q_{i} \times f_{t}, Z_{i}^{\prime}=Z_{i} \times g_{t}$; $R_{i}$ and ${ }^{1} W_{t}$ can be obtain by using equation (4) and equation (1), respectively.

Table 3. The fuzzy overall evaluation of five alternatives

\begin{tabular}{ll}
\hline Alternatives & Overall evaluation \\
\hline$A_{1}$ & $F_{1} \cong 0.2667,0.6637,1.1316$ \\
$A_{2}$ & $F_{2} \cong 0.2798,0.6916,1.1444$ \\
$A_{3}$ & $F_{3} \cong 0.2659,0.6612,1.1312$ \\
$A_{4}$ & $F_{4} \cong 0.2648,0.6578,1.1242$ \\
$A_{5}$ & $F_{5} \cong 0.2768,0.7004,1.1813$ \\
\hline
\end{tabular}

Step 6.

Chen and Hwang [4] made distinctions into four categories between fuzzy ranking methods and fuzzy multiple attribute decision-making methods, left and right score method. 
According to Chen [5] which revised the Chang and Chen's ranking method [3], the ranking values $U_{T}\left(F_{i}\right)$ can be approximately obtained by

$U_{T}\left(F_{i}\right) \cong \hat{a}\left(Z^{\prime}{ }_{i}-x_{1}\right)\left(x_{2}-x_{1}-Q_{i}^{\prime}+Z_{i}^{\prime}\right)$

$+(1-\hat{a}) \times\left[1-\left(x_{2}-Y^{\prime}{ }_{i}\right)\left(x_{2}-x_{1}+Q_{i}^{\prime}-Y^{\prime}{ }_{i}\right)\right]$

for $i \quad 1,2, \ldots, m$;

where $\hat{a}$ is the index of optimism in multi-person decision making proposed by Chen [5].

$x_{1}=\min \left\{Y_{{ }_{1}}, Y_{2}^{\prime}, \ldots, Y_{m}^{\prime}\right\}_{2}$

$x_{2}=\max \left\{Z^{\prime}{ }_{1}, Z^{\prime}{ }_{2}, \ldots, Z^{\prime}{ }_{m}\right\}$,

By using equation $(6)$, we obtain the ranking value of $F_{i}$ as shown in Table 4 .

Table 4. The ranking values of the fuzzy overall evaluation for the five alternatives

\begin{tabular}{llllll}
\hline Alternatives & $A_{1}$ & $A_{2}$ & $A_{3}$ & $A_{4}$ & $A_{5}$ \\
\hline$U_{T}\left(F_{i}\right)$ & 0.5227 & 0.5394 & 0.5214 & 0.5184 & 0.5458 \\
\hline Step 7. & & & & &
\end{tabular}

Therefore, it is obvious that the most credible firms of the five LCD companies in Taiwan is $A_{5}$, i.e., Auo Optronics corp.

\section{Conclusion}

In this paper, a decision algorithm based on the fuzzy set theory is proposed to evaluate the credibility of five LCD panel manufacturing companies in Taiwan. Through the concept of internal credit rating approach proposed by Basel II and the importance analysis, a hierarchical structure for evaluating the credibility of the LCD panel companies on the basis of fuzzy set theory is constructed. The weights of four criteria are determined by analytic hierarchy process based on pair-wise comparison. The fuzzy overall evaluation of each alternative comes from fuzzy multi-criteria decision making method through hierarchy aggregation. By using the revised Chang and Chen's [3] method proposed in this paper, we can determine the credibility rank of fuzzy comprehensive evaluation for the five LCD companies in Taiwan.

\section{References}

[1]R. C. Anderson, D. M. Reeb, Founding-family ownership and firm performance: Evidence from the S\&P 500, The Journal of Finance 58(3) (2003) 1301-1327.

[2]L. Balthazar, PD estimates for Basel II, Risk 17(4) (2004) 84-85.

[3]P. L. Chang, Y. C. Chen, A fuzzy multi-criteria decision making method for technology transfer strategy selection in biotechnology, Fuzzy Sets and Systems 63 (1994) 131-139.
[4]S. J. Chen, C. L. Hwang, Fuzzy Multiple Attribute Decision-making, Methods and Applications, Springer, Heidelberg, 1993.

[5]Y. C. Chen, An application of fuzzy set theory to the external performance evaluation of distribution centers in logistics, Soft Computing 6 (2002) 64-70.

[6]S. Claessens, S. Djankov, L. H. P. Lang, The separation of ownership and control in East Asian corporations, Journal of Financial Economics 58(1-2) (2000) 81-112.

[7]S. Claessens, J. P. H. Fan, Corporate governance in Asia: A survey, International Review of Finance 3(2) (2002) 71-103.

[8]D. Dubois, H. Prade, Operating on fuzzy numbers, International Journal of Systems Science 9 (1978) 613-629.

[9]T. H. Hsu, The fuzzy Delphi analytic hierarchy process, International Journal of Fuzzy Systems 4 (1) (1998) 59-72.

[10]G. J. Klir, Z. Wang, D. Harmanec, Constructing fuzzy measures in expert systems, Fuzzy Sets and Systems 92 (2) (1997) 251-264.

[11]Y. C. Lu, C. J. Lee, Corporate Governance, Quality of financial information, and macroeconomic variables on the prediction power of financial distress of listed companies in Taiwan, The 2005 International Conference on Business and Finance, Taipei, Taiwan, 2004, pp.26-50.

[12]D. Martin, Early warning of bank failure: A logit regression approach, Journal of Banking and Finance 1 (1) (1977) 249-276.

[13]R. La Porta, F. Lopez-de-Silanes, A. Shleifer, Corporate ownership around the world, Journal of Finance 54 (2) (1999) 471-517.

[14]T. L. Saaty, The Analytic Hierarchy Process, McGraw Hill, New York, 1980.

[15]R. B. Whitaker, The early stages of financial distress, Journal of Economics and Finance 23(1) (1999) 123-133.

[16]Y. H. Yeh, T. S. Lee, T. Woidtke, Family control and corporate governance: Evidence from Taiwan, International Review of Finance 2(1) (2001) 21-48.

[17]L. A. Zadeh, Fuzzy Sets, Information and Control 8 (1965) 338-353.

[18]L. A. Zadeh, The concept of a linguistic variable and its application to approximate reasoning, Information Sciences 9 ( III ) (1976) 43-80

[19]M. E. Zmijewski, Financial ratio and the probabilistic prediction of bankruptcy, Journal of Accounting Research 22 (1) (1984) 59-86. 